\title{
Management of relapsed/refractory marginal zone lymphoma: focus on ibrutinib
}

This article was published in the following Dove Press journal: Cancer Management and Research

\section{Nathan M Denlinger Narendranath Epperla Basem MWilliam}

Department of Internal Medicine, The Ohio State University Comprehensive Cancer Center (OSUCCC-James),

The Ohio State University, Columbus, $\mathrm{OH}$, USA
Correspondence: Basem M William The Ohio State University, $320 \mathrm{~W}$, 10th Avenue - A352, Columbus, $\mathrm{OH}$ 43210, USA

$\mathrm{Tel}+\mathrm{I} 6146887942$

Fax + I 6I4 2937526

Email basem.william@osumc.edu

\begin{abstract}
Marginal zone lymphomas (MZLs) consist of a diverse family of malignancies, which are derived from B-cells. The disease subtypes are recognized extranodal, nodal, and splenic MZLs. The disease characteristics, clinical course, and treatment vary considerably based on the site of involvement. In 2017, the US Food and Drug Administration approved ibrutinib, a first in class Bruton's tyrosine kinase inhibitor that revolutionized the care of chronic lymphocytic leukemia patients; for, the treatment of relapsed/refractory MZL based on pivotal open-label Phase II trial demonstrated an overall response rate of $48 \%$, with a complete response rate of $3 \%$, median progression-free survival of 14.2 months, and median overall survival not yet reached at a median follow-up of 19.4 months. In this review, we aim to summarize the current conundrums in the management of MZL and the evolving role of ibrutinib in the treatment of MZL. Keywords: non-Hodgkin's lymphoma, marginal zone, ibrutinib
\end{abstract}

\section{Introduction}

Marginal zone lymphoma (MZL) is the third most common lymphoma, accounting for $8 \%-12 \%$ of all B-cell non-Hodgkin's lymphomas (NHL). ${ }^{1,2}$ MZL originates from memory B lymphocytes harbored in the marginal zone of secondary lymphoid follicles present in the spleen, mucosa-associated lymphoid tissues, and rarely lymph nodes. ${ }^{3}$ The development of MZL is associated with chronic antigen-mediated B-cell receptor (BCR) activation in most cases. ${ }^{4-7}$ The Surveillance, Epidemiology, and End Results (SEER) data have shown that MZL occurs in adults with a median age of 67 years, but with a slight female predominance. ${ }^{8-10}$ Based on the involved sites and characteristic molecular findings, the World Health Organization classified MZL into 3 specific subtypes, each with its own unique epidemiology, clinical presentation, and therapeutic options. ${ }^{1}$ These subtypes include extranodal marginal zone lymphoma (EMZL), also called mucosa-associated lymphatic tissue (MALT) lymphoma; splenic MZL (SMZL); and nodal MZL (NMZL). ${ }^{1}$

Over the past 5-7 years, a greater understanding of the disease biology, including genetic and molecular characterization, has changed the therapeutic landscape of MZL. Novel pharmaceutical engineering approaches focusing on intracellular signaling pathways have resulted in targeted therapies that have improved efficacy and tolerable toxicity profiles. There has been a growing evidence on the role played by the BCR signaling pathway in the pathogenesis of B-cell lymphoproliferative disorders, including MZL. ${ }^{11-13}$ In many of these malignancies, small molecule kinase inhibitors targeting BCR signaling, such as the Bruton's tyrosine kinase (BTK) inhibitor (ibrutinib), seem 
to provide new avenues of therapeutic strategies. ${ }^{12}$ Here, we provide a brief overview of the various subtypes of MZL, discuss in detail the management of MZL, and focus on the emerging role of ibrutinib in this realm.

\section{$M Z L-a$ heterogeneous disease entity: epidemiology and presentation \\ EMZL \\ Epidemiology of EMZL}

EMZL, also called MALT lymphoma, is the most common subtype of MZL, accounting for $\sim 70 \%$ of all MZLs. ${ }^{14}$ Median age at diagnosis is $50-60$ years. ${ }^{15}$ EMZL can originate at virtually any extranodal site and arises in organs that normally lack lymphoid tissue (eg, stomach, intestine, thyroid, lung, and skin). Pathogenesis of EMZL involves continued proliferation of $B$ cells and persistent stimulation of the BCR signaling pathway. The latter seems to be induced by chronic inflammation ${ }^{16-21}$ as a result of both infectious and autoimmune causes. Examples of infectious and EMZL correlative relationships include gastric EMZL arising from Helicobacter pylori, MZL localized to the skin and Borrelia burgdorferi, the ocular adnexa and Chlamydophila psittaci, the small intestine and Campylobacter jejuni, and possibly the lung with Achromobacter xylosoxidans. The most frequently affected organ in EMZL is the stomach, and there is compelling evidence for a causal relationship between H. pylori and gastric EMZL. ${ }^{5-7,22}$ Chronic hepatitis $\mathrm{C}$ viral (HCV) infection has been implicated in the pathogenesis of all MZL subtypes ${ }^{21,23-26}$ and mainly affects the non-gastric sites, often the salivary or lacrimal glands in EMZL. Autoimmune diseases also increase the risk of non-gastric EMZL at various anatomical sites; for example, primary Sjogren's syndrome results in a greatly increased risk for salivary gland EMZL, and Hashimoto's thyroiditis has been implicated in the development of thyroid EMZL. ${ }^{27-31}$

\section{Presentation of EMZL}

EMZL most commonly presents as extranodal disease and is limited to the site of origin (Ann Arbor stage IE); peripheral lymph node and bone marrow (BM) involvement is uncommon. ${ }^{32}$ Diagnosis is made by tissue biopsy, with confirmation of diagnosis by an expert hematopathologist to avoid overtreatment of benign reactive conditions or other lymphoma entities. ${ }^{33}$ Clinical signs and symptoms of EMZL may vary according to the site of primary location. ${ }^{33}$ Gastric EMZL is most common, accounting for one-third of all sites of localization and frequently presents with early-stage localized disease, while disseminated disease is more common with primary non-gastric sites. ${ }^{34-38}$

\section{SMZL}

\section{Epidemiology of SMZL}

SMZL arises predominantly from the marginal zone memory B-cells located in the follicles of the spleen, splenic hilar lymph nodes, BM, and the peripheral blood. ${ }^{39} \mathrm{SMZL}$ accounts for $\sim 20 \%$ of all MZLs, ${ }^{1,40}$ and the median age of occurrence is 69 years. ${ }^{41}$ The pathogenesis of SMZL has yet to be fully understood; similar to other subtypes of MZL, it likely involves the persistent stimulation of BCR signaling pathway, with increasing proliferation and survival of malignant B cells. ${ }^{13}$ Though the association between HCV infection and SMZL has been described, there seems to be some geographic difference given the variation in seroprevalence from one series to the other. ${ }^{42-44}$

\section{Presentation of SMZL}

Most SMZL patients are asymptomatic at the time of presentation with anemia, thrombocytopenia, or lymphocytosis incidentally found on routine blood test. Subsequent referral to the hematologist and further workup then may reveal SMZL. Advanced stage SMZL, however, can present with massive splenomegaly, abdominal pain, and early satiety. Symptomatic cytopenias may be present, and imaging may show splenic hilar lymphadenopathy. ${ }^{45} \mathrm{Up}$ to $20 \%$ of patients also present with autoimmune manifestations, including hemolytic anemia, immune thrombocytopenia, and acquired coagulation disorders. ${ }^{42,46}$ Definitive diagnosis can be made from histopathologic evaluation of the spleen, which shows a nodular lymphoid proliferation with a biphasic appearance effacing the white pulp, involving the red pulp in a patchy fashion, and infiltrating the vessel wall. If histopathologic evaluation of the spleen is unavailable, diagnosis can be made by immunophenotyping of peripheral blood cells coupled with the histopathologic evaluation of the BM showing intrasinusoidal infiltration of CD20+ cells. ${ }^{1,47,48}$

\section{NMZL}

\section{Epidemiology of NMZL}

NMZL is the least common subtype of MZL, representing $<2 \%$ of all NHL and $\sim 10 \%$ of all MZLs. ${ }^{1}$ The median age of patients diagnosed with NMZL is between 50 and 60 years. ${ }^{49}$ The molecular pathogenesis of NMZL is still incompletely described but likely involves constitutive BCR signaling, resulting in proliferation and survival of malignant B cells. ${ }^{50}$ 


\section{Presentation of NMZL}

Similar to other indolent nodal lymphomas, such as small lymphocytic lymphoma and follicular lymphoma (FL), the majority of patients with NMZL present with non-bulky disseminated peripheral, abdominal, and thoracic lymph node involvement. ${ }^{51,52} \mathrm{~B}$ symptoms are rare, and diagnosis requires exclusion of splenic and other organ involvement to distinguish it from other subtypes of MZL. Though involvement of BM can occur in about one-third of patients, peripheral blood involvement and cytopenias are rare..$^{51,53}$

\section{Management of MZL Frontline treatment of MZL}

Frontline therapy for MZL differs greatly based upon the subtype and underlying etiology. For example, a significant proportion of patients with HCV and EMZL will note regression of the lymphomatous process after undergoing antiviral treatment for HCV infection. ${ }^{24,26,54-60}$ Thus, antiviral therapy for $\mathrm{HCV}$ is recommended for all cases of MZL associated with HCV infection.

\section{EMZL}

In patients with gastric EMZL that are positive for H. pylori, antibiotics targeting $H$. pylori are the initial treatment of choice. With documented H. pylori eradication, the majority of $H$. pylori-positive patients (up to 75\%) will go into remission. ${ }^{61}$ However, $\sim 50 \%$ of patients with gastric H. pyloripositive EMZL will have relapse/progressive disease with antibiotic therapy alone ${ }^{62,63}$ and require further therapy. A smaller proportion of $H$. pylori-negative gastric EMZL patients and those with non-gastric EMZL (with or without a known causative microbial agent) will respond to antibiotics alone. Hence, it is reasonable in most patients to attempt antibiotic therapy as a first-line therapy; however, most will require alternative and subsequent therapy ${ }^{64-70}$ Though detailed guidelines for response assessment and follow-up have been published, ${ }^{33}$ there are no consensus guidelines with regard to the optimal second-line treatment after initial therapy failure ${ }^{35,37,38,71}$ Involved-field radiotherapy (IFRT) (dose of 25-35 Gy) is a reasonable first-line (in H. pylorinegative cases) or second-line option (in H. pylori-positive cases who fail $H$. pylori eradication therapy) for patients with localized disease, providing excellent local disease control, though distant failures still occur. ${ }^{72-77}$ Rituximab can be used alternatively if IFRT is not possible. With disseminated gastric or non-gastric disease, observation may be an adequate initial approach.
In patients who require systemic treatment, various combinations have been used and studied. The $2013 \mathrm{StiL}$ trial looked at previously untreated indolent lymphoma and compared the standard of therapy, rituximab plus cyclophosphamide, doxorubicin, vincristine, and prednisone (R-CHOP), to a combination of bendamustine plus rituximab. ${ }^{78}$ They found that compared with R-CHOP, the combination of bendamustine and rituximab (BR) had increased progression-free survival (PFS), and there were fewer adverse events (AEs). ${ }^{78}$ Salar et al subsequently investigated BR specifically in EMZL and had good outcomes. ${ }^{79}$ Thus, historically for EMZL, bendamustine plus rituximab have been used as an active and well-tolerated first-line treatment. ${ }^{79}$ More recently, the final results of the randomized multicenter IELSG-19 trial were published ${ }^{80}$ This randomized trial focused specifically on frontline therapy for EMZL and included 3 arms: chlorambucil monotherapy, chlorambucil plus rituximab, and rituximab monotherapy ${ }^{80}$ What they found was that, between arms, overall survival (OS) was without significant difference ${ }^{80}$ However, the chlorambucil plus rituximab arm did provide significantly improved eventfree survival (EFS) and PFS, ${ }^{80}$ and thus, the combination of rituximab with chlorambucil has gained traction as the initial treatment of choice for EMZL.

\section{SMZL}

Asymptomatic patients with SMZL can undergo observation for multiple years with routine clinical examinations and blood counts; observation in these patients does not influence overall outcomes. $^{81,82}$ Based on the consensus guidelines, treatment for SMZL is only indicated for symptomatic splenomegaly, progressive nodal disease, symptomatic cytopenias, and/or autoimmune cytopenias..$^{47,55,59}$ Initial treatment options include splenectomy, rituximab alone, and chemotherapy combined with rituximab. ${ }^{83-88}$ Conventionally, initial treatment for patients with symptomatic splenomegaly and/or cytopenias secondary to splenic sequestration was splenectomy, and patients could remain disease-free for many years after the surgery. ${ }^{42,81,82,89,90}$ More recently, rituximab-based therapy has become a first-line alternative to splenectomy with outcomes comparable with or better than splenectomy. ${ }^{55,59,84,86,91-94} \mathrm{~A}$ combination of rituximab and chemotherapy is indicated for those with disseminated disease, constitutional symptoms, and/or having signs of high-grade transformation. ${ }^{55,59}$

\section{NMZL}

There are no treatment guidelines focusing specifically on NMZL. Treatment and management typically follow that of 
similarly staged FL. ${ }^{59}$ In localized disease, targeted radiotherapy is appropriate, while in both limited and advancedstage diseases with low tumor burden, watchful waiting is employed. No trials to date have looked at NMZL specifically; however, with more advanced-stage disseminated disease requiring treatment, immunochemotherapy regimens comprising rituximab plus chemotherapy with or without an anthracycline are typically used.

\section{Management of relapsed/refractory $(R / R)$ MZL}

Treatment for R/R MZL is similar to that of advanced stage or disseminated MZL. It is typically approached in a manner similar to other indolent B-cell lymphomas, such as FL. ${ }^{55}$ Unfortunately, patients with MZL are often excluded from larger studies of more common indolent B-cell lymphomas, and thus, no disease-specific treatment guidelines have been developed. ${ }^{12}$ Only smaller disease-specific trials have been performed and must be used in conjunction with extrapolation from larger studies in which MZL was included to assist with optimization of treatment choice.

Across MZL subtypes, if no prior immunochemotherapy has been received, various regimens combining rituximab and chemotherapy-containing regimens have classically been the initial treatment of choice, resulting in overall response rate (ORR) of $85 \%-93 \%$ and complete response rate (CR) of $54 \%-78 \%{ }^{80,95-98}$ Grade III-IV myelosuppression is common with these regimens and may exclude some patients from eligibility for these therapies. ${ }^{12}$

Autologous and allogeneic hematopoietic progenitor cell transplantation (HCT) has been performed in selected patients with $\mathrm{R} / \mathrm{R}$ MZL, achieving durable remissions and frequently cures, albeit at cost of significant morbidity. ${ }^{99,100}$ Though standardized guidelines for selecting R/R MZL appropriate for HCT are lacking due to a paucity of data, ${ }^{101-103}$ HCT can be utilized with excellent outcomes in selected fit patients having aggressively behaving disease. ${ }^{99,100}$ Autologous transplant is usually indicated in fit patients with transformation to aggressive lymphoma. Chimeric antigen receptor-modified T-cells have consistently demonstrated activity in advanced hematologic malignancies, including different types of lymphomas, and clinical trials are underway in patients with various types of indolent B-cell lymphomas (including MZL). ${ }^{104}$

\section{R/R EMZL}

The optimal treatment of R/R EMZL remains to be defined. For patients who have progressed after local therapy, single-agent rituximab or multiple rituximab-based chemotherapy combinations are usually employed. In the IELSG19 study, the combination of rituximab with chlorambucil resulted in superior EFS and PFS compared with rituximab and chlorambucil monotherapy. However, this study focused on first-line therapy; only $8 \%$ of patients were enrolled after treatment failure, and OS was similar in both groups. ${ }^{80}$ Thus, though further investigation into the combination of chlorambucil and rituximab, if not previously used, may be warranted, for patients failing locally therapy, single-agent rituximab is still the preferred first option. ${ }^{80} \mathrm{BR}$ regimen has gained popularity in the US for excellent tolerance and superior outcomes in other indolent B-cell lymphomas. ${ }^{105}$ ORR of $93 \%$ has been achieved in patients with R/R EMZL (CR $71 \%$ ) with the $\mathrm{BR}$ regimen with durable remissions at a cost of $29 \%$ incidence of Grade III-IV hematological toxicity. ${ }^{106}$ The proteasome inhibitor bortezomib also has significant single-agent activity in R/R EMZL with an ORR of $48 \%$ (CR 31\%). ${ }^{107}$ Similar impressive results were noted when bortezomib was combined with rituximab in R/R MZL. ${ }^{108}$ ORR of up to $80 \%$ (with $54 \%$ CRs) were also reported with the combination of rituximab with the immunomodulating agent lenalidomide, with no unexpected toxicities. ${ }^{109}$

\section{R/R SMZL}

$\mathrm{R} / \mathrm{R}$ patients with SMZL include those who failed local treatment (splenectomy) and those progressing on rituximab monotherapy. Though rituximab-based chemotherapy combinations can be employed in this setting, ${ }^{55,59}$ treatment, or retreatment in patients who previously receiving rituximab monotherapy is a commonly employed and retains its efficacy in most cases. ${ }^{10,111} \mathrm{BR}$ has also gained popularity as a preferred regimen in R/R SMZL based on the impressive ORR (92\%) observed in the BRIGHT study in MZL patients $(n=25) .{ }^{112}$

\section{R/R NMZL}

Though no studies have specifically looked at R/R NMZL, strategies comparable with similarly staged FL are used, and combination therapies with immunochemotherapy are most typical. ${ }^{50}$ Good outcomes have been seen in some studies with bortezomib in particular, which has shown promising activity specifically when looking at NMZL. ${ }^{107,113,114}$

\section{Prognosis of MZL EMZL}

The natural history of EMZL is indolent, and SEER analysis shows 5-year OS rate of $88.7 \%$ and median OS 12.6 years. ${ }^{10}$ Median time to progression is better for GI compared with 
non-GI EMZL $;^{74}$ however, GI and pulmonary involvement had a worse survival compared with other locations, with a 5 -year incidence rate of lymphoma-related death of 9.5\%$14.3 \%$ compared with $4.5 \%-7.8 \%$, respectively. ${ }^{10}$ For patients not responding to antibiotics, with Stage IE-IIE EMZL treated with IFRT only, OS at 10 years is $79 \%-87 \% .^{74,75}$ Outcomes for high-dose systemic therapy/autologous hematopoietic stem cell transplantation in disseminated EMZL are similar to those in FL. ${ }^{102,103}$ Enrollment in clinical trials is highly encouraged given the limited therapeutic options in R/R EMZL. ${ }^{101}$ Despite frequent relapses, EMZL often maintains a relatively indolent course. ${ }^{35}$ Relapses most commonly occur in the tissue of origin; however, involvement of other sites (including lymph nodes) can occur. ${ }^{115}$ Using the data from IELSG-19 trial, Thieblemont et al reported MALT-IPI (International Prognostic Index) as a prognostic tool for risk stratifying patients with MALT. Patient who were $\geq 70$ years, with advanced stage (Ann Arbor Stage III or IV) and elevated lactate dehydrogenase $(\mathrm{LDH})$ conferred poor outcomes in EMZL patients. Based on the presence of 0, 1, and 2 or more risk factors, the patients were stratified into low-, intermediate-, and high-risk groups. ${ }^{116}$

\section{SMZL}

Though the majority of SMZL run an indolent course similar to EMZL, overall, SMZL has poorer outcomes due to a relatively larger proportion of patients who present with aggressive disease. ${ }^{117}$ The median OS for SMZL is $\sim 8-10$ years; ${ }^{10,43}$ however, in cases of aggressive disease $(-25 \%-30 \%$ of cases), the median survival is $<4$ years. ${ }^{43,117}$ In SMZL, the Italian Foundation of Lymphomas prognostication index can be used to risk stratify patients by presence of risk factors, including low hemoglobin, elevated LDH, and reduced albumin level at diagnosis. The 5-year disease-specific survival rate was $88 \%$ in the low-risk group, $73 \%$ in the moderaterisk group, and 50\% in the high-risk group..$^{43}$ Subsequently, other prognostic models were also developed ${ }^{118,119}$ to optimize prognostication and can therefore be used. However, these models are based on clinical parameters and are not $100 \%$ sensitive or specific. Hence, incorporation of mutational/ genetic markers into the current clinical prognostic models may be required in the future to improve risk stratification of SMZL patients.

\section{NMZL}

The overall prognosis for NMZL is worse than EMZL when presenting as disseminated disease ${ }^{120}$ and more comparable with SMZL and other indolent lymphomas. ${ }^{10,50,121}$ To date, this disease remains incurable and is characterized a pattern of recurring relapse at nodal sites. ${ }^{50}$ With the advent of newer therapies, the average 5-year OS of NMZL has reached 70\%-90\%. ${ }^{122}$ Both the IPI and the FL International Prognostic Index are used in NMZL to stratify patients into high and low risk..$^{50,122}$

\section{Role of ibrutinib in MZL - is it ready for primetime?}

The importance of the role played by BCR signaling in the development of MZL cannot be undermined. ${ }^{11,13}$ BTK plays a key role in the BCR signaling pathway and has been shown to be involved in the formation, survival, and proliferation of malignant B cells. ${ }^{123-126}$ The efficacy of Food and Drug Administration (FDA)-approved ibrutinib in other lymphoid malignancies, including chronic lymphocytic leukemia, small lymphocytic lymphoma, mantle cell lymphoma, and Waldenstrom's macroglobulinemia is well known. ${ }^{12}$ Given the likely importance of BCR, induced by chronic antigenic stimulation, in the development of MZL, ${ }^{4}$ it was theorized that BTK targeting may play a role in therapy for R/R MZL. A Phase I trial of single-agent ibrutinib in 56 patients with heavily pre-treated B-cell malignancies (median number of prior therapies $=3$ ) included 4 patients with $\mathrm{R} / \mathrm{R}$ MZL; 1 patient sustained a partial response and 3 had stable disease, ${ }^{127}$ thus opening the window for further studies.

Subsequently, a pivotal, Phase II open-label international study was conducted using ibrutinib in patients with $R / R$ MZL previously treated with rituximab-based therapy. ${ }^{12}$ The study included 60 evaluable patients who were treated with single-agent ibrutinib (560 mg orally daily) administered until progression or unacceptable toxicity. ORR was $48 \%$ and median PFS was 14.2 months. CR was noted in 2 patients $(3 \%)$. Progression of disease was the main reason for treatment discontinuation, occurring in $32 \%$ of study participants. Though AEs occurred in $44 \%$ of patients, the rates of treatment discontinuation and dose reduction due to AEs were relatively low at $17 \%$ and $10 \%$, respectively. These were comparable with rates of discontinuation due to AE seen in other similar studies with ibrutinib. At a median follow-up of 19.4 months, $38 \%$ still remained on ibrutinib, and median OS has not been reached.

Outcomes were also analyzed by MZL subtype. Median PFS was 13.8 months for EMZL, 19.4 months for SMZL, and 8.3 months for NMZL. Estimated 18-month OS rate was $81 \%$, and of the 8 patients who died during the study, $4(7 \%)$ were attributable to progression of disease. At the time, this study was published (19 months from start date), 
the median duration of response has not yet been reached. Overall, the rate of disease control based on clinical benefit was $83 \%$, and $78 \%$ of patients were shown to have reduced tumor burden. Clinical response to ibrutinib was seen in all subtypes. Response occurred in those treated with prior chemotherapy, immunotherapy, or a combination of the two. Responses were seen in both relapsed and refractory patients as well as those with bulky disease and/or BM involvement. ${ }^{12}$

Based on these results, FDA granted accelerated approval for ibrutinib for the treatment of R/R MZL requiring systemic therapy and progressing on at least 1 prior anti-CD20-based therapy. It is noteworthy that, prior to ibrutinib, no therapeutic agent had been approved by the FDA specifically for treatment of MZL. Currently, ibrutinib provides a viable alternative treatment option to chemoimmunotherapy for the treatment of R/R MZL. ${ }^{12}$

Compared with MZL, ibrutinib has shown only modest activity in FLR/R FL. A recent Phase II consortium trial of 40 patients with R/R FL has shown ORR of $37.5 \%$ with CR of 12.25, median PFS of 14 months, and 2-year PFS of $20.4 \%$. Response rates were significantly higher among patients whose disease was sensitive to rituximab $(52.6 \%)$ compared with those who were rituximab refractory $(16.7 \%)$. CARD11 mutations were present in $16 \%(5 / 31)$ of patients and predicted resistance to ibrutinib. ${ }^{128}$ This is in contrast to an ORR of $82 \%$ with CR $27 \%$ in untreated FL in the Phase II PCYC-1125-CA study that included 80 patients, with the majority having Stage III/IV disease. In that same trial, the median PFS and OS has not been reached as only 5 patients had disease progression. ${ }^{129}$ Ibrutinib was well-tolerated in both trials with low incidence of AEs.

Combination therapies that include BTK inhibition as well as other agents are currently ongoing and have much potential. Currently, a randomized, double-blind, multicenter Phase III trial, SELENE, is underway. This trial is investigating ibrutinib vs placebo in combination with either BR or R-CHOP (rituximab, cyclophosphamide, doxorubicin, vincristine, and prednisone) in patients with previously treated MZL or FL (NCT01974440). The primary objective is to determine whether ibrutinib vs placebo in combination with BR or R-CHOP will prolong PFS, with secondary objectives, including OS, CR, ORR, safety, and toxicity. ${ }^{130}$ With the advent of novel combination approaches with more tolerable side effects and improved efficacy, there is hope that optimal and standardized treatment regimens for MZL may soon be around the corner. Ibrutinib is also being investigated in combination with lenalidomide \pm rituximab (NCT02532257 and NCT01955499); selinexor (KPT-330), a selective inhibitor of nuclear export (NCT02303392); the check point inhibitor pembrolizumab (NCT02332980); and other target agents in R/R MZL and other B-cell malignancies.

\section{Future directions}

In the current landscape, standardized treatment algorithms still lack sufficient evidence-based guidelines required to guide optimal therapy. Obinutuzumab, which has shown efficacy in FL, is currently being tested both in combination with chlorambucil and bendamustine in current Phase III trials for MZL. ${ }^{131,132}$ However, Herold et al recently reported the results of a subset of patients in the randomized Gallium trial comparing obinutuzumab or rituximab in patients with previously untreated advanced stage MZL. ${ }^{133}$ This study did show a significant difference in PFS between arms and actually showed increased frequency and severity of AEs. ${ }^{133}$ Other investigatory trials continue to be underway looking for other efficacious novel agents.

\section{Conclusion}

MZL is a relatively rare and heterogeneous malignancy of B-cells that makes dedicated clinical trials difficult to perform and for which standardized treatment regimens are unfortunately lacking. Though each subtype has a unique initial treatment strategy based on limited-stage disease characteristics, with more advanced stage disease and $R / R$ MZL, regimens used for advanced FL are usually employed. Though smaller studies have specifically looked at chemoimmunotherapy regimens for $\mathrm{R} / \mathrm{R} M Z \mathrm{~L}$, consensus evidence-based guidelines on treatment specific to MZL are lacking. A recent pivotal Phase II trial has shown that single-agent ibrutinib is both a safe and efficacious treatment for all subtypes R/R MZL. Based on this, ibrutinib is rapidly gaining popularity as an agent of choice in MZL that progresses after rituximab-based therapy. Future studies will inform about the role of singleagent ibrutinib in both treatment-naïve patients, and its role in $\mathrm{R} / \mathrm{R}$ MZL in combination with other agents.

\section{Disclosure}

The authors report no conflicts of interest in this work.

\section{References}

1. Swerdlow SH, Campo E, Pileri S, et al. The 2016 revision of the World Health Organization classification of lymphoid neoplasms. Blood. 2016;127(20):2375-2390.

2. Al-Hamadani M, Habermann TM, Cerhan JR, Macon WR, Maurer MJ, Go RS. Non-Hodgkin lymphoma subtype distribution, geodemographic patterns, and survival in the US: a longitudinal analysis of the National Cancer Data Base from 1998 to 2011. Am J Hematol. 2015;90(9):790-795. 
3. Weill JC, Weller S, Reynaud CA. Human marginal zone B cells. Annu Rev Immunol. 2009;27:267-285.

4. Quinn ER, Chan CH, Hadlock KG, Foung SK, Flint M, Levy S. The B-cell receptor of a hepatitis $\mathrm{C}$ virus ( $\mathrm{HCV}$ )-associated non-Hodgkin lymphoma binds the viral E2 envelope protein, implicating HCV in lymphomagenesis. Blood. 2001;98(13):3745-3749.

5. Zucca E, Bertoni F, Roggero E, et al. Molecular analysis of the progression from Helicobacter pylori-associated chronic gastritis to mucosa-associated lymphoid-tissue lymphoma of the stomach. $N$ Engl J Med. 1998;338(12):804-810.

6. Zucca E, Bertoni F, Vannata B, Cavalli F. Emerging role of infectious etiologies in the pathogenesis of marginal zone B-cell lymphomas. Clin Cancer Res. 4;20(20):5207-5216.

7. Kuo SH, Cheng AL. Helicobacter pylori and mucosa-associated lymphoid tissue: what's new. Hematology Am Soc Hematol Educ Program. 2013;2013:109-117.

8. Khalil MO, Morton LM, Devesa SS, et al. Incidence of marginal zone lymphoma in the United States, 2001-2009 with a focus on primary anatomic site. Br J Haematol. 2014;165(1):67-77.

9. Surveillance, Epidemiology, and End Results (SEER) Program (www. seer.cancer.gov) Research Data (1973-2014). In: National Cancer Institute D, Surveillance Research Program, ed released April 2017, based on the November 2016 submission.

10. Olszewski AJ, Castillo JJ. Survival of patients with marginal zone lymphoma: analysis of the Surveillance, Epidemiology, and End Results database. Cancer. 2013;119(3):629-638.

11. Niemann CU, Wiestner A. B-cell receptor signaling as a driver of lymphoma development and evolution. Semin Cancer Biol. 2013;23(6): 410-421.

12. Noy A, de Vos S, Thieblemont C, et al. Targeting Bruton tyrosine kinase with ibrutinib in relapsed/refractory marginal zone lymphoma. Blood. 2017;129(16):2224-2232.

13. Yan Q, Huang Y, Watkins AJ, et al. BCR and TLR signaling pathways are recurrently targeted by genetic changes in splenic marginal zone lymphomas. Haematologica. 2012;97(4):595-598.

14. A clinical evaluation of the International Lymphoma Study Group classification of non-Hodgkin's lymphoma. The Non-Hodgkin's Lymphoma Classification Project. Blood. 1997;89(11):3909-3918.

15. Cohen SM, Petryk M, Varma M, Kozuch PS, Ames ED, Grossbard ML. Non-Hodgkin's lymphoma of mucosa-associated lymphoid tissue. Oncologist. 2006;11(10):1100-1117.

16. Dierlamm J, Baens M, Wlodarska I, et al. The apoptosis inhibitor gene API2 and a novel 18q gene, MLT, are recurrently rearranged in the $\mathrm{t}(11 ; 18)(\mathrm{q} 21 ; \mathrm{q} 21)$ associated with mucosa-associated lymphoid tissue lymphomas. Blood. 1999;93(11):3601-3609.

17. Willis TG, Jadayel DM, Du MQ, et al. Bcl10 is involved in $\mathrm{t}(1 ; 14)$ (p22; 32 ) of MALT B cell lymphoma and mutated in multiple tumor types. Cell. 1999;96(1):35-45.

18. Streubel B, Lamprecht A, Dierlamm J, et al. T(14;18)(q32;q21) involving IGH and MALT1 is a frequent chromosomal aberration in MALT lymphoma. Blood. 2003;101(6):2335-2339.

19. Rinaldi A, Mian M, Chigrinova E, et al. Genome-wide DNA profiling of marginal zone lymphomas identifies subtype-specific lesions with an impact on the clinical outcome. Blood. 2011;117(5):1595-1604.

20. Kwee I, Rancoita PM, Rinaldi A, et al. Genomic profiles of MALT lymphomas: variability across anatomical sites. Haematologica. 2011;96(7):1064-1066.

21. Suarez F, Lortholary O, Hermine O, Lecuit M. Infection-associated lymphomas derived from marginal zone B cells: a model of antigendriven lymphoproliferation. Blood. 2006;107(8):3034-3044.

22. O'Rourke JL. Gene expression profiling in Helicobacter-induced MALT lymphoma with reference to antigen drive and protective immunization. J Gastroenterol Hepatol. 2008;23(Suppl 2):S151-S156.

23. Bracci PM, Benavente Y, Turner JJ, et al. Medical history, lifestyle, family history, and occupational risk factors for marginal zone lymphoma: the InterLymph Non-Hodgkin Lymphoma Subtypes Project. J Natl Cancer Inst Monogr. 2014;2014(48):52-65.
24. Arcaini L, Burcheri S, Rossi A, et al. Prevalence of HCV infection in nongastric marginal zone B-cell lymphoma of MALT. Ann Oncol. 2007;18(2):346-350.

25. Arcaini L, Merli M, Volpetti S, Rattotti S, Gotti M, Zaja F. Indolent B-cell lymphomas associated with HCV infection: clinical and virological features and role of antiviral therapy. Clin Dev Immunol. 2012;2012:638185

26. Hermine O, Lefrère F, Bronowicki JP, et al. Regression of splenic lymphoma with villous lymphocytes after treatment of hepatitis $\mathrm{C}$ virus infection. N Engl J Med. 2002;347(2):89-94.

27. Derringer GA, Thompson LD, Frommelt RA, Bijwaard KE, Heffess CS, Abbondanzo SL. Malignant lymphoma of the thyroid gland: a clinicopathologic study of 108 cases. Am J Surg Pathol. 2000;24(5): 623-639.

28. Manganelli P, Fietta P, Quaini F. Hematologic manifestations of primary Sjögren's syndrome. Clin Exp Rheumatol. 2006;24(4):438-448.

29. Zintzaras E, Voulgarelis M, Moutsopoulos HM. The risk of lymphoma development in autoimmune diseases: a meta-analysis. Arch Intern Med. 2005;165(20):2337-2344.

30. Nocturne G, Mariette X. Sjögren Syndrome-associated lymphomas: an update on pathogenesis and management. $\mathrm{Br}$ J Haematol. 2015;168(3):317-327.

31. Wang SS, Vajdic CM, Linet MS, et al. Associations of non-Hodgkin Lymphoma (NHL) risk with autoimmune conditions according to putative NHL loci. Am J Epidemiol. 2015;181(6):406-421.

32. Starr AG, Caimi PF, Fu P, et al. Dual institution experience of extranodal marginal zone lymphoma reveals excellent long-term outcomes. Bri J Haematol. 2016;173(3):404-412.

33. Zucca E, Copie-Bergman C, Ricardi U, et al. Gastric marginal zone lymphoma of MALT type: ESMO Clinical Practice Guidelines for diagnosis, treatment and follow-up. Ann Oncol. 2013;24(Suppl 6):vi144-vi148.

34. Zinzani PL. The many faces of marginal zone lymphoma. Hematol Am Soc Hematol Educ Program. 2012;2012:426-432.

35. Zucca E, Conconi A, Pedrinis E, et al. Nongastric marginal zone B-cell lymphoma of mucosa-associated lymphoid tissue. Blood. 2003;101(7):2489-2495.

36. Thieblemont C, Bastion Y, Berger F, et al. Mucosa-associated lymphoid tissue gastrointestinal and nongastrointestinal lymphoma behavior: analysis of 108 patients. J Clin Oncol. 1997;15(4):1624-1630.

37. Raderer M, Wöhrer S, Streubel B, et al. Assessment of disease dissemination in gastric compared with extragastric mucosa-associated lymphoid tissue lymphoma using extensive staging: a single-center experience. J Clin Oncol. 2006;24(19):3136-3141.

38. de Boer JP, Hiddink RF, Raderer M, et al. Dissemination patterns in non-gastric MALT lymphoma. Haematologica. 2008;93(2):201-206.

39. Boveri E, Arcaini L, Merli M, et al. Bone marrow histology in marginal zone B-cell lymphomas: correlation with clinical parameters and flow cytometry in 120 patients. Ann Oncol. 2009;20(1):129-136.

40. Armitage JO, Weisenburger DD. New approach to classifying nonHodgkin's lymphomas: clinical features of the major histologic subtypes. Non-Hodgkin's Lymphoma Classification Project. J Clin Oncol. 1998;16(8):2780-2795.

41. Liu L, Wang H, Chen Y, Rustveld L, Liu G, Du XL. Splenic marginal zone lymphoma: a population-based study on the 2001-2008 incidence and survival in the United States. Leuk Lymphoma. 2013;54(7): 1380-1386.

42. Thieblemont C, Felman P, Berger F, et al. Treatment of splenic marginal zone B-cell lymphoma: an analysis of 81 patients. Clin Lymphoma. 2002;3(1):41-47.

43. Arcaini L, Lazzarino M, Colombo N, et al. Splenic marginal zone lymphoma: a prognostic model for clinical use. Blood. 2006;107(12): 4643-4649.

44. Arcaini L, Paulli M, Boveri E, et al. Splenic and nodal marginal zone lymphomas are indolent disorders at high hepatitis $\mathrm{C}$ virus seroprevalence with distinct presenting features but similar morphologic and phenotypic profiles. Cancer. 2004;100(1):107-115. 
45. Starr AG, Caimi PF, Fu P, et al. Splenic marginal zone lymphoma: excellent outcomes in 64 patients treated in the rituximab era. Hematology. 2017;22(7):405-411.

46. Parry-Jones N, Matutes E, Gruszka-Westwood AM, Swansbury GJ, Wotherspoon AC, Catovsky D. Prognostic features of splenic lymphoma with villous lymphocytes: a report on 129 patients. $B r J$ Haematol. 2003;120(5):759-764.

47. Matutes E, Oscier D, Montalban C, et al. Splenic marginal zone lymphoma proposals for a revision of diagnostic, staging and therapeutic criteria. Leukemia. 2008;22(3):487-495.

48. Ponzoni M, Kanellis G, Pouliou E, et al. Bone marrow histopathology in the diagnostic evaluation of splenic marginal-zone and splenic diffuse red pulp small B-cell lymphoma: a reliable substitute for spleen histopathology? Am J Surg Pathol. 2012;36(11):1609-1618.

49. Arcaini L, Lucioni M, Boveri E, Paulli M. Nodal marginal zone lymphoma: current knowledge and future directions of an heterogeneous disease. Eur J Haematol. 2009;83(3):165-174.

50. Thieblemont C, Molina T, Davi F. Optimizing therapy for nodal marginal zone lymphoma. Blood. 2016;127(17):2064-2071.

51. Arcaini L, Paulli M, Burcheri S, et al. Primary nodal marginal zone B-cell lymphoma: clinical features and prognostic assessment of a rare disease. Br J Haematol. 2007;136(2):301-304.

52. van den Brand M, van der Velden WJ, Diets IJ, et al. Clinical features of patients with nodal marginal zone lymphoma compared to follicular lymphoma: similar presentation, but differences in prognostic factors and rate of transformation. Leuk Lymphoma. 2016;57(7):1649-1656.

53. Starr AG, Caimi PF, Fu P, et al. Dual institution experience of nodal marginal zone lymphoma reveals excellent long-term outcomes in the rituximab era. Br J Haematol. 2016;175(2):275-280.

54. Vallisa D, Bernuzzi P, Arcaini L, et al. Role of anti-hepatitis C virus (HCV) treatment in HCV-related, low-grade, B-cell, nonHodgkin's lymphoma: a multicenter Italian experience. J Clin Oncol. 2005;23(3):468-473.

55. Dreyling M, Thieblemont C, Gallamini A, et al. ESMO Consensus conferences: guidelines on malignant lymphoma. part 2: marginal zone lymphoma, mantle cell lymphoma, peripheral T-cell lymphoma. Ann Oncol. 2013;24(4):857-877.

56. Vannata B, Zucca E. Hepatitis C virus-associated B-cell nonHodgkin lymphomas. Hematology Am Soc Hematol Educ Program. 2014;2014(1):590-598.

57. Michot JM, Canioni D, Driss H, et al. Antiviral therapy is associated with a better survival in patients with hepatitis $\mathrm{C}$ virus and $\mathrm{B}$-cell nonHodgkin lymphomas, ANRS HC-13 lympho-C study. Am J Hematol. 2015;90(3):197-203.

58. Arcaini L, Besson C, Peveling-Oberhag J, et al. Anti-lymphoma activity of interferon-free antiviral treatment in patients with indolent B-cell lymphomas associated with hepatitis $\mathrm{C}$ virus infection. In: Besson C, editor. Vol 126. Blood Ame Soc Hematol. 2015;126:3938.

59. Tarella C, Arcaini L, Baldini L, et al. Italian Society of Hematology, Italian Society of Experimental Hematology, and Italian Group for Bone Marrow Transplantation guidelines for the management of indolent, nonfollicular B-cell lymphoma (marginal zone, lymphoplasmacytic, and small lymphocytic lymphoma). Clin Lymphoma Myeloma Leuk. 2015;15(2):75-85.

60. Arcaini L, Vallisa D, Rattotti S, et al. Antiviral treatment in patients with indolent B-cell lymphomas associated with HCV infection: a study of the Fondazione Italiana Linfomi. Ann Oncol. 2014;25(7):1404-1410.

61. Zullo A, Hassan C, Cristofari F, et al. Effects of Helicobacter pylori eradication on early stage gastric mucosa-associated lymphoid tissue lymphoma. Clin Gastroenterol Hepatol. 2010;8(2):105-110.

62. Malfertheiner P, Megraud F, O'Morain C, et al. Current concepts in the management of Helicobacter pylori infection: the Maastricht III Consensus Report. Gut. 2007;56(6):772-781.

63. Chey WD, Wong BC, Gastroenterology PPCotACo. American College of Gastroenterology guideline on the management of Helicobacter pylori infection. Am J Gastroenterol. 2007;102(8):1808-1825.
64. Ferreri AJ, Dolcetti R, Du MQ, et al. Ocular adnexal MALT lymphoma: an intriguing model for antigen-driven lymphomagenesis and microbial-targeted therapy. Ann Oncol. 2008;19(5):835-846.

65. Govi S, Dolcetti R, Ponzoni M, et al. Final results of a multicenter phase II trial with translational elements to investigate the possible infective causes of ocular adnexal marginal zone B-cell lymphoma (OAMZL) with particular reference to chlamydia species and the efficacy of doxycycline as first-line lymphoma treatment (the IELSG\#27 TRIAL). In: Dolcetti R, editor. Vol 118. Blood Am Soc Hematol. 2011; 118:267.

66. Zullo A, Hassan C, Ridola L, et al. Eradication therapy in Helicobacter pylori-negative, gastric low-grade mucosa-associated lymphoid tissue lymphoma patients: a systematic review. J Clin Gastroenterol. 2013;47(10):824-827.

67. Kiesewetter B, Raderer M. Antibiotic therapy in nongastrointestinal MALT lymphoma: a review of the literature. Blood. 2013;122(8): 1350-1357.

68. Lecuit M, Lortholary O. Immunoproliferative small intestinal disease associated with Campylobacter jejuni. Med Mal Infect. 2005;35(Suppl 2):S56-S58

69. Ferreri AJ, Govi S, Ponzoni M. Marginal zone lymphomas and infectious agents. Semin Cancer Biol. 2013;23(6):431-440.

70. Ferreri AJ, Govi S, Pasini E, et al. Chlamydophila psittaci eradication with doxycycline as first-line targeted therapy for ocular adnexae lymphoma: final results of an international phase II trial. J Clin Oncol. 2012;30(24):2988-2994.

71. Thieblemont C, Berger F, Dumontet C, et al. Mucosa-associated lymphoid tissue lymphoma is a disseminated disease in one third of 158 patients analyzed. Blood. 2000;95(3):802-806.

72. Yahalom J. MALT lymphomas: a radiation oncology viewpoint. Ann Hematol. 2001;80(Suppl 3):B100-B105.

73. Koch P, Probst A, Berdel WE, et al. Treatment results in localized primary gastric lymphoma: data of patients registered within the German multicenter study (GIT NHL 02/96). J Clin Oncol. 2005;23(28): 7050-7059.

74. Goda JS, Gospodarowicz M, Pintilie M, et al. Long-term outcome in localized extranodal mucosa-associated lymphoid tissue lymphomas treated with radiotherapy. Cancer. 2010;116(16):3815-3824.

75. Teckie S, Qi S, Lovie S, et al. Long-term outcomes and patterns of relapse of early-stage extranodal marginal zone lymphoma treated with radiation therapy with curative intent. Int J Radiat Oncol Biol Phys. 2015;92(1):130-137.

76. Wirth A, Gospodarowicz M, Aleman BM, et al. Long-term outcome for gastric marginal zone lymphoma treated with radiotherapy: a retrospective, multi-centre, International Extranodal Lymphoma Study Group study. Ann Oncol. 2013;24(5):1344-1351.

77. (NCCN). NCCN. National Comprehensive Cancer Network guidelines V.2.2013: non-Hodgkin's lymphoma. National Comprehensive Cancer Network Guidelines; 2013. Available from: http://www.nccn. org/professionals/ physician_gls/PDF/nhl.pdf. Accessed November 11,2013

78. Rummel MJ, Niederle N, Maschmeyer G, et al. Bendamustine plus rituximab versus $\mathrm{CHOP}$ plus rituximab as first-line treatment for patients with indolent and mantle-cell lymphomas: an open-label, multicentre, randomised, phase 3 non-inferiority trial. Lancet. 2013;381(9873):1203-1210.

79. Salar A, Domingo-Domenech E, Panizo C, et al. First-line responseadapted treatment with the combination of bendamustine and rituximab in patients with mucosa-associated lymphoid tissue lymphoma (MALT2008-01): a multicentre, single-arm, phase 2 trial. Lancet Haematol. 2014;1(3):e104-e111.

80. Zucca E, Conconi A, Martinelli G, et al. Final results of the IELSG-19 randomized trial of mucosa-associated lymphoid tissue lymphoma: improved event-free and progression-free survival with rituximab plus chlorambucil versus either chlorambucil or rituximab monotherapy. J Clin Oncol. 2017;35(17):1905-1912. 
81. Thieblemont C, Felman P, Callet-Bauchu E, et al. Splenic marginalzone lymphoma: a distinct clinical and pathological entity. Lancet Oncol. 2003;4(2):95-103.

82. Chacón JI, Mollejo M, Muñoz E, et al. Splenic marginal zone lymphoma: clinical characteristics and prognostic factors in a series of 60 patients. Blood. 2002;100(5):1648-1654.

83. Olszewski AJ. Survival outcomes with and without splenectomy in splenic marginal zone lymphoma. Am J Hematol. 2012;87(11): E119-E122.

84. Kalpadakis C, Pangalis GA, Angelopoulou MK, et al. Treatment of splenic marginal zone lymphoma with rituximab monotherapy: progress report and comparison with splenectomy. Oncologist. 2013; 18(2):190-197.

85. Lefrère F, Hermine O, Belanger C, et al. Fludarabine: an effective treatment in patients with splenic lymphoma with villous lymphocytes. Leukemia. 2000;14(4):573-575.

86. Kalpadakis C, Pangalis GA, Dimopoulou MN, et al. Rituximab monotherapy is highly effective in splenic marginal zone lymphoma. Hematol Oncol. 2007;25(3):127-131.

87. Arcaini L, Orlandi E, Scotti M, et al. Combination of rituximab, cyclophosphamide, and vincristine induces complete hematologic remission of splenic marginal zone lymphoma. Clin Lymphoma. 2004;4(4):250-252.

88. Iannitto E, Luminari S, Tripodo C, et al. Rituximab with cyclophosphamide, vincristine, non-pegylated liposomal doxorubicin and prednisone as first-line treatment for splenic marginal zone lymphoma: a Fondazione Italiana Linfomi phase II study. Leuk Lymphoma. 2015;56(12):3281-3287.

89. Lenglet J, Traullé C, Mounier N, et al. Long-term follow-up analysis of 100 patients with splenic marginal zone lymphoma treated with splenectomy as first-line treatment. Leuk Lymphoma. 2014;55(8): 1854-1860.

90. Troussard X, Valensi F, Duchayne E, et al. Splenic lymphoma with villous lymphocytes: clinical presentation, biology and prognostic factors in a series of 100 patients. Groupe Francais d'Hématologie Cellulaire (GFHC). Br J Haematol. 1996;93(3):731-736.

91. Bennett M, Schechter GP. Treatment of splenic marginal zone lymphoma: splenectomy versus rituximab. Semin Hematol. 2010;47(2):143-147.

92. Kalpadakis C, Pangalis GA, Vassilakopoulos TP, Sachanas S, Angelopoulou MK. Treatment of splenic marginal zone lymphoma: should splenectomy be abandoned? Leuk Lymphoma. 2014;55(7): 1463-1470.

93. Bennett M, Yegena S, Dave HP, Schechter GP. Re: rituximab monotherapy is highly effective in splenic marginal zone lymphoma. Hematol Oncol. 2008;26(2):114.

94. Else M, Marín-Niebla A, de la Cruz F, et al. Rituximab, used alone or in combination, is superior to other treatment modalities in splenic marginal zone lymphoma. Br J Haematol. 2012;159(3): 322-328.

95. Brown JR, Friedberg JW, Feng Y, et al. A phase 2 study of concurrent fludarabine and rituximab for the treatment of marginal zone lymphomas. Br J Haematol. 2009;145(6):741-748.

96. Cervetti G, Galimberti S, Sordi E, et al. Significant efficacy of 2-CdA with or without rituximab in the treatment of splenic marginal zone lymphoma (SMZL). Ann Oncol. 2010;21(4):851-854.

97. Orciuolo E, Buda G, Sordi E, et al. 2CdA chemotherapy and rituximab in the treatment of marginal zone lymphoma. Leuk Res. 2010;34(2):184-189.

98. Laribi K, Tempescul A, Ghnaya H, et al. The bendamustine plus rituximab regimen is active against primary nodal marginal zone B-cell lymphoma. Hematol Oncol. 2016;35(4):536-541.

99. Thieblemont C, Coiffier B. Management of marginal zone lymphomas. Curr Treat Options Oncol. 2006;7(3):213-222.

100. Avivi I, Arcaini L, Ferretti V, et al. High dose therapy and autologous stem cell transplantation in marginal zone lymphoma: an EBMT-FILgimeto retrospective study. Blood. 2014;124:2526.
101. Bertoni F, Coiffier B, Salles G, et al. MALT lymphomas: pathogenesis can drive treatment. Oncology (Williston Park). 2011;25(12):1134$1142,1147$.

102. Li L, Bierman P, Vose J, Loberiza F, Armitage JO, Bociek RG. Highdose therapy/autologous hematopoietic stem cell transplantation in relapsed or refractory marginal zone non-Hodgkin lymphoma. Clin Lymphoma Myeloma Leuk. 2011;11(3):253-256.

103. Brown JR, Gaudet G, Friedberg JW, et al. Autologous bone marrow transplantation for marginal zone non-Hodgkin's lymphoma. Leuk Lymphoma. 2004;45(2):315-320.

104. Locke FL, Neelapu SS, Bartlett NL, et al. Clinical and biologic covariates of outcomes in ZUMA-1: a pivotal trial of axicabtagene ciloleucel (axi-cel; KTE-C19) in patients with refractory aggressive non-Hodgkin lymphoma (r-NHL). J Clin Oncol. 2017;35(15 Suppl):7512.

105. Gil L, Kazmierczak M, Kroll-Balcerzak R, Komarnicki M. Bendamustine-based therapy as first-line treatment for non-Hodgkin lymphoma. Med Oncol. 2014;31(5):944.

106. Kiesewetter B, Mayerhoefer ME, Lukas J, Zielinski CC, Müllauer $\mathrm{L}$, Raderer M. Rituximab plus bendamustine is active in pretreated patients with extragastric marginal zone B cell lymphoma of the mucosa-associated lymphoid tissue (MALT lymphoma). Ann Hematol. 2014;93(2):249-253

107. Conconi A, Martinelli G, Lopez-Guillermo A, et al. Clinical activity of bortezomib in relapsed/refractory MALT lymphomas: results of a phase II study of the International Extranodal Lymphoma Study Group (IELSG). Ann Oncol. 2011;22(3):689-695.

108. de Vos S, Goy A, Dakhil SR, et al. Multicenter randomized phase II study of weekly or twice-weekly bortezomib plus rituximab in patients with relapsed or refractory follicular or marginal-zone B-cell lymphoma. J Clin Oncol. 2009;27(30):5023-5030.

109. Kiesewetter B, Willenbacher E, Willenbacher W, et al. A phase II study of rituximab plus lenalidomide for mucosa-associated lymphoid tissue lymphoma (MALT lymphoma). Blood. 2017;129(3):383-385.

110. Kalpadakis C, Pangalis GA, Angelopoulou MK, Vassilakopoulos TP. Treatment of splenic marginal zone lymphoma. Best Pract Res Clin Haematol. 2017;30(1-2):139-148.

111. Bennett M, Sharma K, Yegena S, Gavish I, Dave HP, Schechter GP. Rituximab monotherapy for splenic marginal zone lymphoma. Haematologica. 2005;90(6):856-858.

112. Flinn IW, van der Jagt R, Kahl BS, et al. Randomized trial of bendamustine-rituximab or R-CHOP/R-CVP in first-line treatment of indolent NHL or MCL: the BRIGHT study. Blood. 2014;123(19):2944-2952.

113. Troch M, Jonak C, Müllauer L, et al. A phase II study of bortezomib in patients with MALT lymphoma. Haematologica. 2009;94(5):738-742.

114. O'Connor OA, Wright J, Moskowitz C, et al. Phase II clinical experience with the novel proteasome inhibitor bortezomib in patients with indolent non-Hodgkin's lymphoma and mantle cell lymphoma. J Clin Oncol. 2005;23(4):676-684.

115. Zucca E, Bertoni F. The spectrum of MALT lymphoma at different sites: biological and therapeutic relevance. Blood. 2016;127(17):2082-2092.

116. Thieblemont $\mathrm{C}$, Cascione L, Conconi A, et al. A MALT lymphoma prognostic index. Blood. 2017;130(12):1409-1417.

117. Bertoni F, Zucca E. State-of-the-art therapeutics: marginal-zone lymphoma. J Clin Oncol. 2005;23(26):6415-6420.

118. Montalbán C, Abraira V, Arcaini L, et al. Risk stratification for Splenic Marginal Zone Lymphoma based on haemoglobin concentration, platelet count, high lactate dehydrogenase level and extrahilar lymphadenopathy: development and validation on 593 cases. Br J Haematol. 2012;159(2): 164-171

119. Montalban C, Abraira V, Arcaini L, et al. Simplification of risk stratification for splenic marginal zone lymphoma: a point-based score for practical use. Leuk Lymphoma. 2014;55(4):929-931.

120. Kuper-Hommel MJ, van de Schans SA, Vreugdenhil G, van Krieken JH, Coebergh JW. Trends in incidence, therapy and outcome of localized nodal and extranodal marginal zone lymphomas: declining incidence and inferior outcome for gastrointestinal sites. Leuk Lymphoma. 2013;54(9):1891-1897. 
121. Berger F, Felman P, Thieblemont C, et al. Non-MALT marginal zone B-cell lymphomas: a description of clinical presentation and outcome in 124 patients. Blood. 2000;95(6):1950-1956.

122. Heilgeist A, McClanahan F, Ho AD, Witzens-Harig M. Prognostic value of the Follicular Lymphoma International Prognostic Index score in marginal zone lymphoma: an analysis of clinical presentation and outcome in 144 patients. Cancer. 2013;119(1):99-106.

123. Bernard S, Danglade D, Gardano L, et al. Inhibitors of BCR signalling interrupt the survival signal mediated by the micro-environment in mantle cell lymphoma. Int J Cancer. 2015;136(12):2761-2774.

124. de Gorter DJ, Beuling EA, Kersseboom R, et al. Bruton's tyrosine kinase and phospholipase Cgamma2 mediate chemokine-controlled B cell migration and homing. Immunity. 2007;26(1):93-104.

125. de Rooij MF, Kuil A, Geest CR, et al. The clinically active BTK inhibitor PCI-32765 targets B-cell receptor- and chemokine-controlled adhesion and migration in chronic lymphocytic leukemia. Blood. 2012;119(11):2590-2594.

126. Ponader S, Chen SS, Buggy JJ, et al. The Bruton tyrosine kinase inhibitor PCI-32765 thwarts chronic lymphocytic leukemia cell survival and tissue homing in vitro and in vivo. Blood. 2012;119(5):1182-1189.

127. Advani RH, Buggy JJ, Sharman JP, et al. Bruton tyrosine kinase inhibitor ibrutinib (PCI-32765) has significant activity in patients with relapsed/refractory B-cell malignancies. J Clin Oncol. 2013;31(1):88-94.
128. Bartlett NL, Costello BA, LaPlant BR, et al. Single-agent ibrutinib in relapsed or refractory follicular lymphoma: a phase 2 consortium trial. Blood. 2017;131(2):182-190.

129. Fowler N, Nastoupil L, de Vos S, et al. Ibrutinib plus rituximab in treatment-naive patients with follicular lymphoma: results from a multicenter, phase 2 study. Blood. 2015;126(23):470.

130. Fowler NH. A phase 3 study of ibrutinib in combination with either bendamustine and rituximab (BR) or rituximab, cyclophosphamide, doxorubicin, vincristine, and prednisone (R-CHOP) in patients with previously treated follicular lymphoma or marginal zone lymphoma. In: Hiddemann W, editors. Vol 32. 2014 ASCO Annual Meeting. J Clin Oncol. 2014:32.

131. Goede V, Fischer K, Busch R, et al. Obinutuzumab plus chlorambucil in patients with CLL and coexisting conditions. N Engl J Med. 2014; 370(12):1101-1110.

132. Sehn LH, Chua N, Mayer J, et al. Obinutuzumab plus bendamustine versus bendamustine monotherapy in patients with rituximabrefractory indolent non-Hodgkin lymphoma (GADOLIN): a randomised, controlled, open-label, multicentre, phase 3 trial. Lancet Oncol. 2016;17(8):1081-1093.

133. Herold M, Hoster E, Janssens A, et al. Immunochemotherapy with obinutuzumab or rituximab in a subset of patients in the randomised gallium trial with previously untreated marginal zone lymphoma (MZL). Hematol Oncol. 2017;35:146-147.
Cancer Management and Research

\section{Publish your work in this journal}

Cancer Management and Research is an international, peer-reviewed open access journal focusing on cancer research and the optimal use of preventative and integrated treatment interventions to achieve improved outcomes, enhanced survival and quality of life for the cancer patient. The manuscript management system is completely online and includes

\section{Dovepress}

a very quick and fair peer-review system, which is all easy to use. Visit http://www.dovepress.com/testimonials.php to read real quotes from published authors. 